\title{
The Economics of Standards Wars
}

\author{
VICTOR STANGO*
}

Federal Reserve Bank of Chicago

\begin{abstract}
Policymakers face an increasing number of questions regarding whether markets efficiently choose technological standards. In this essay I survey the economic literature regarding standards, focusing on arguments that markets move between standards either too slowly or too swiftly.
\end{abstract}

\section{Introduction}

The rapid pace of technological change in the last two decades has highlighted the strong link between technological standards, market performance and economic welfare. Consequently, the question of whether markets settle on efficient standards is drawing considerable attention from policymakers and researchers. A related question is whether non-market institutions such as standards bodies can improve upon market-mediated standards outcomes. Both of these questions relate to a larger policy issue: whether public sector involvement in standard-setting is justified.

In this essay I survey the economic literature regarding standards wars. I begin by sketching the economics of standards. This initial discussion parallels that in other surveys of standards. ${ }^{1}$ I then discuss key points in the intellectual debate regarding standards wars. Finally, I discuss some research that advances the debate and outline gaps in the literature. To narrow the discussion, I focus on the academic literature on standards; there is a large case literature that informs the standards debate, which I mention only briefly. ${ }^{2}$

\footnotetext{
* Senior Economist, Federal Reserve Bank of Chicago, 230 South LaSalle Street, Chicago IL 60604. Phone: (312)-322-6835. Email: victor.stango@chi.frb.org Thanks to Carrie Jankowski and Kaushik Murali for research assistance, and to Editor Julian Wright, Ed Green, Chris Knittel, Tom Ciesielski and a referee for helpful comments. The views expressed here do not reflect the views of the Federal Reserve Bank of Chicago or the Federal Reserve System.

${ }^{1}$ David and Greenstein (1990) is the most comprehensive and closely related.

${ }^{2}$ David and Greenstein (1990) is a good reference on the case literature prior to 1990 . The case studies in Besen and Johnson (1986), Gabel (1987, 1991), Postrel (1990) and Grindley (1995) are also informative. Kahin and Abbate (1995) contains case studies that also focus on the institutional setting surrounding industry standards bodies.
} 


\section{Standards and standards wars}

Standards are specifications that determine the compatibility of different products. ${ }^{3}$ For example, audio playback technology has had several standards during the last three decades: LPs, audiocassettes, eight-tracks, CDs, and more recently MP3s. These technologies are differentiated not only by their characteristics (such as sound quality and production cost), but also by the fact that music recorded on one standard cannot be played back using the equipment of another standard. Standards with similar features include video playback, where the Betamax and VHS standards competed in the early 1980s, and home video games, where a variety of standards have competed since the 1980s. These products are system goods, where a standard is defined as a set of components (such as playback equipment and recorded media) that are compatible with one another.

Other standards allow adopters to form a communication network. In this case, standards define the ability of network users to communicate with one another. The early days of personal computers, when Mac and PC users could not exchange files, are good examples. The Mac and PC operating systems represent different standards for file exchange.

While standards recently have come to the fore of policy discussions in high-tech markets, standards act similarly in many traditional markets. Nuts on the Metric standard will only work with Metric bolts. Razors manufactured by Schick will not work with Gillette razor blades. One can extend the intuition of a standard to even more abstract notions of networks. The English language, for example, is a communication standard.

\subsection{Standardization and standards wars}

Standards are interesting from an economic standpoint because many markets face a strong trend toward standardization - the adoption of a common standard by all market participants. This leads markets toward "winner-take-all" outcomes where a single standard emerges victorious, while the others disappear. These battles are known as standards wars.

Markets may exhibit stronger or weaker trends toward standardization. In some cases, adoption of a common standard or resolution of a standards war is swift and complete. In others, standards wars are long and bloody. As an example, when Philips developed the compact disc standard, it faced battles both with existing standards such as LPs and audiocassettes in the 1980s and with newer digital alternatives such as DAT. The sponsors of the digital technologies standardized fairly quickly, coming to agreements under which Philips licensed its technology to other firms in the market. On the other hand, the battle between CDs and the existing music standards took many years to resolve. Similar examples can be found in the case literature.

Standards wars can arise in two ways. First, a new technology may come to market that is fundamentally incompatible with the old. This is the case with analog vs. digital music recording. A second possibility is that producers could intentionally design technologies to be incompatible. Home video game systems are an example of this sort of incompatibility. The economics in the second instance are more complex, because they involve conscious decisions by producers to choose incompatibility. For the most part, in the discussion

\footnotetext{
${ }^{3}$ This usage does not refer to quality or reference standards.
} 
below I abstract from the compatibility choice. ${ }^{4}$ I focus on standards wars in general, taking as given that the market exhibits competition between incompatible technologies.

\subsection{The importance of network effects}

A common theme running through the literature on standards wars is that trends toward standardization increase when there are network effects. Network effects are complementary relationships in value creation among adopters of a common standard. ${ }^{5}$ Returning to the examples discussed earlier, for communication networks the network effect is that operating on a common standard allows communication with more users, which is valuable. This is a direct network effect or network externality, in that adoption per se confers a benefit on others. All else equal, the existence of a strong direct network effect pushes the market toward adoption of a single standard, because adopters benefit most when all users are on the same standard.

Another sort of network effect is an indirect network effect. This type of network effect arises in markets for system goods such as video game consoles. In these markets adoption itself does not confer benefits on other users of the system. However, it is still the case that adoption might ultimately benefit others. For example, greater adoption of Playstation consoles should generate greater variety in Playstation game titles. Widespread adoption allows producers to achieve scale more easily.

The distinction between direct and indirect network effects seems subtle, but it has important economic implications. For example, the notion that direct network effects lead to market failure is more widely accepted than the notion that indirect network effects lead to market failure. I expand upon this point below.

\subsection{Sponsored vs. unsponsored and de facto vs. de jure standards}

Standards fall into broad categories based on two features: whether the standard is sponsored or unsponsored, and whether it is a de facto or de jure standard. Sponsored standards can be used only by the holder(s) of property rights to the standard. ${ }^{6}$ For example, patented technologies for new standards are sponsored. Compact disk technology fell into this category at its inception, although Philips has since licensed the technology to other industry participants. On the other hand, unsponsored standards can be used by anyone. For example, any wrench manufacturer can build a Metric wrench without purchasing the rights to do so. Many compatibility standards are simply technical specifications allowing interoperability. These standards can be as simple as a number of pins used to connect two components, or a number of data fields used to carry an electronic record. These are similarly unsponsored. The primary economic impact of the distinction between sponsored and unsponsored standards is the mechanism through which standards

\footnotetext{
${ }^{4}$ There are two lines of research in this area. One addresses compatibility between (horizontally) competing networks when there are network externalities. See Besen and Farrell (1994) for a survey. The other addresses compatibility between components in system markets. Katz and Shapiro (1994) is a good survey. The Katz and Shapiro survey also deals with issues related to standards wars; I reference their discussion below. See Gandal (2002) for a survey of some public policy issues related to compatibility and standardization. These public policy issues are related to the literature on tying, which can be viewed as a form of incompatibility. See Carlton and Waldman (2002), Choi and Stefanadis (2001), and Church and Gandal $(1996,2000)$ for analyses of tying in system markets.

${ }^{5}$ For a comprehensive survey of the broader literature on network effects, see Farrell and Klemperer (2003).

${ }^{6}$ Some use the terms proprietary and non-proprietary in place of sponsored and unsponsored.
} 
are chosen. With unsponsored standards, demand-side decisions by consumers are the sole driver of adoption for new standards. This implies that consumer expectations and their ability to coordinate with one another are key. With sponsored technologies, adoption depends not only on demand-side behavior but on the strategic behavior of firms owning standards. Because sponsors of new standards have a profit motive in spurring adoption, they can use a variety of price and non-price mechanisms to influence consumers' adoption decisions. Wars between sponsored standards are therefore typically more complex than wars between unsponsored standards.

Another distinction is between de facto and de jure standards. ${ }^{7}$ De facto standards are those that achieve adoption through a standards war. De jure standards are those that emerge through industry consensus. This consensus may be informal, formally expressed through an industry standards body, or ratified by a standards organization such as ANSI. ${ }^{8}$ De jure standards are rarely sponsored. In cases where a sponsored standard is considered for de jure ratification, it is often a condition of ratification that the sponsor must surrender property rights to the standard. In contrast to de jure standards, de facto standards are often sponsored. Microsoft's Windows operating system is a sponsored de facto standard.

I focus on de facto standards most closely in the discussion here, since they are the outcome of standards wars. Nonetheless, one can also think of de jure standards as arising from standards wars resolved by negotiation through committee. Some of the literature below explicitly compares de facto and de jure processes of resolving standards wars.

\section{The economic literature on standards wars}

The focus of the literature on standards wars has been identifying situations in which a market chooses an inefficient standard, or becomes "locked-in" to an old standard even when confronted with a new, superior standard. These questions are important because if markets do not choose the right standards or migrate efficiently between standards, there is scope for government intervention to improve on market outcomes.

\subsection{The early theoretical literature: lock-in, path dependence and excess inertia}

In general, the term lock-in refers to a situation in which economic agents' equilibrium decisions regarding standards adoption yield lower social welfare than an alternative. The alternative may also be an equilibrium; a fundamental feature of markets where there are network effects is the existence of multiple equilibria in adoption. ${ }^{9}$ Communication networks are classic examples of markets that might exhibit multiple equilibria, because they display strong network externalities. Consider the decision faced by adopters of a new

\footnotetext{
${ }^{7}$ This terminology is not universal, although my usage is consistent with that in David and Greenstein (1990). Farrell (1989) distinguishes between formal and informal standards (along the same lines as my use of de jure and de facto). Farrell (1996) distinguishes between de jure standards achieved through standards wars and those achieved through standards bodies, and terms the latter consensus standards. Outside of the economics literature, it is common to observe the term "standard" used only in reference to de jure standards. ${ }^{8}$ The American National Standards Institute (ANSI) is a sub-group of ISO (the International Standards Organization) handling standards in the United States. ISO is an umbrella group containing a host of standards bodies.

${ }^{9}$ See Farrell and Klemperer (2003) for a discussion and examples.
} 
communication standard such as the fax machine. If no consumers have fax machines, then no one consumer will want to adopt the first fax machine, because a fax machine has no stand-alone value if it can not communicate with other machines. Thus, adoption by none is an equilibrium. There may be other equilibria as well, involving adoption by many or all consumers. But the fact that the market can become locked-in at zero adoption is a potentially serious concern, because society as a whole is worse off at zero adoption than unanimous adoption. Of course, if market participants can coordinate their behavior, they might be able to jointly choose the efficient standard; lock-in will only occur if there is coordination failure.

An early paper modeling the circumstances under which the market might become locked-in is Arthur (1989). ${ }^{10}$ Arthur outlines a model of adopter choice between two unsponsored technologies in which adopters may face what Arthur calls increasing returns. These increasing returns are network externalities: benefits to adoption that increase with the number of other consumers adopting the same technology. Arthur does not directly motivate his work as explaining economies' failure to efficiently choose or move between standards, but he notes several anecdotal examples from the case literature on standards (e.g., narrow gauge railroads). ${ }^{11}$

Arthur provides general conditions under which a market will become locked in to an inferior standard. His definition of lock-in is a situation in which a government subsidy could not move the market toward the more efficient standard. The manner in which lockin occurs in Arthur's model is a function of the timing of adoption and payoffs. He posits a situation in which adopters move sequentially, and more importantly receive payoffs that are a function of the number of adopters that have previously chosen each standard. In this setting, standards adoption displays path dependence: later adopters' decisions depend strongly on the decisions of previous adopters. In this situation, it is possible that early adopters choose the "inefficient" standard. An inefficient standard is one such that at some point in the adoption process, a different prior adoption path would have yielded greater total benefits to all adopters. Intuitively, such a standard would be one with high intrinsic benefits to early adopters but small network effects. ${ }^{12}$ This standard would "win", because its high intrinsic benefits are attractive to early adopters when the network is small. However, it becomes inefficient as later adopters come on board because it generates relatively small network benefits. A key assumption of Arthur's model is that economic agents must move sequentially in their adoption decisions. Arthur also assumes that agents must commit to a standard and cannot defer adoption. Nor does Arthur allow coordination or side-payments among the adopters.

Farrell and Saloner (1985) examine a sequential unsponsored standard adoption game with network externalities. Farrell and Saloner focus on the impact of imperfect information. They note that when agents are certain about other agents' benefits from adoption, then adoption decisions are always efficient. This result holds even if agents have different preferences for the new standard.

When agents are uncertain about each others' benefits from adoption, the market can exhibit what Farrell and Saloner call excess inertia: the propensity to become trapped on

\footnotetext{
${ }^{10}$ Arthur (1996) provides more detail on lock-in.

${ }^{11}$ Similarly, some of the work below refers generally to technology adoption with network effects rather than the adoption of standards per se. I use the term standard throughout for consistency.

${ }^{12}$ Intrinsic benefits are those received by the adopter regardless of the number of other adopters.
} 
an inferior standard..$^{13}$ The intuition Farrell and Saloner describe is a situation in which "[b]oth firms are fence-sitters, happy to jump on the bandwagon if it gets rolling but insufficiently keen to set it rolling themselves". Interestingly, Farrell and Saloner note that pre-play communication may exacerbate excess inertia when agents have different preferences for the new standard. This occurs because adopters misrepresent their preferences in order to influence the adoption decisions of others. This has implications for the performance of standards bodies, which foster pre-commitment communication.

In contrast to the above models in which the standard is unsponsored, Katz and Shapiro (1986) examine competition where one or more standards are sponsored. This is a key distinction in two ways. First, it highlights the importance of property rights for standards. Second, it explicitly models the strategic behavior that arises when standards are sponsored. Katz and Shapiro identify a broad set of features of equilibrium in their model, including whether the market chooses the efficient standard. They differentiate standards by assuming that their relative superiority changes over time (in a two-period model).

As a benchmark result, Katz and Shapiro first establish that price will equal marginal cost when standards are unsponsored and there is free entry. This leads to inefficient adoption of the standard because buyers do not consider the network externality they generate through their adoption; this effect may cause markets to become locked-in on the wrong standard. ${ }^{14}$ Katz and Shapiro also consider an intermediate case, and find that a sponsored but inferior standard may "win" and become locked-in when competing against a superior but unsponsored standard. The intuition for this is that the holder of property rights to a standard will expend monopoly rents to spur adoption by investing in an "installed base".

In analyzing the case of competing sponsored standards, Katz and Shapiro observe the somewhat counter-intuitive outcome that the market may exhibit excess momentum or insufficient friction. ${ }^{15}$ These terms refer to situations in which the market is biased against an old but superior standard, and moves too swiftly to a new but inferior standard. In the Katz and Shapiro model this happens through stranding, in which adopters of one the standard ignore the network benefits that they confer on adopters of the alternative standard.

Later work refines these intuitions and highlights some new insights. Farrell and Saloner (1986) examine a setting in which an older unsponsored standard faces competition from a new, superior unsponsored standard. The novelty of their model is that the older standard has an installed base: a group of users that have committed to using the standard. ${ }^{16}$ The importance of installed base in Farrell and Saloner's model is that it

\footnotetext{
${ }^{13}$ More precisely, Farrell and Shapiro define symmetric excess inertia as a situation in which every adopter prefers the new standard, but that adoption does not occur. They use the term excess inertia to refer more generally to a situation in adoption of the new standard does not occur, even though the market-wide benefits from adoption of the new standard exceed the market-wide benefits from using the old standard. In the second instance, some firms may prefer the old standard.

${ }^{14}$ The externality may cause lock-in, but also may lead to under-adoption of an efficient standard. Underadoption occurs when the standard is adopted by fewer than the socially efficient number of market participants. This can lead to inefficient splitting, in which the market holds more than one standard when it would be optimal for all participants to choose the same standard.

${ }^{15}$ This occurs as a minor case in Farrell and Saloner (1985). Katz and Shapiro (1986) use slightly different language, terming this outcome "excessive foresight".

${ }^{16}$ The bulk of their paper is devoted to a model in which older consumers have committed irrevocably to the old standard, while new consumers can choose between the old and new standards.
} 
highlights the degree to which adopters of a new standard can strand existing users of an older standard; consequently, the model exhibits insufficient friction.

Farrell and Saloner highlight another important issue in standards wars: "preannouncements". In their model, the arrival of the new standard is unanticipated, so a preannouncement notifying consumers of its impending arrival can change adoption decisions. A somewhat surprising result of their analysis is that preannouncements can reduce welfare. This occurs because some consumers who would have adopted the old standard absent the announcement wait for the imminent new standard, strengthening the degree to which users of the old standard are stranded.

Katz and Shapiro (1992) consider the role of installed base in a setting with sponsored standards. ${ }^{17}$ In their model, owners of an old and new standard compete on prices; the owner of the new standard also chooses when to introduce the new standard. Consumers are nonstrategic, in that they take other consumers' adoption decisions as given. ${ }^{18}$ In general, Katz and Shapiro show that the private incentives for new standard introduction exceed social incentives; the new standard comes to market too soon and may take over the market even when such an outcome is not socially desirable. In essence this is because the owner of the new standard can subsidize its (inefficient) adoption.

In summary, this early literature both clarifies the assumptions under which excess inertia can occur, and offers new insight. Chief among these is the ease with which markets may also move too swiftly between standards rather than too slowly. This stands in contrast to the conventional wisdom prior to that point, which held that excess inertia was the only serious concern. The other insights concern mechanisms that one might imagine would resolve excess inertia (or insufficient friction) - such as communication, preannouncements, or sponsorship. In many cases, these factors not only fail to resolve any inefficiency, but in fact can make it worse.

\subsection{The QWERTY example and debate}

The early literature motivates the problems examined in their theoretical analysis by reference to a few classic examples of excess inertia. The most well-known of these is the QWERTY keyboard, so named for the first five letters on the top row. An influential paper by David (1985) argues that the QWERTY keyboard design was chosen early in the market but is inefficient given current standard. In particular, the QWERTY keyboard is designed to minimize key sticking on manual typewriters. The thrust of the argument is that this is no longer a concern. Because computer keyboards cannot stick, there is no gain to a design that minimizes key sticking. Furthermore, the argument is that superior alternatives to the QWERTY design exist in terms of learning costs and ultimate typing speed, and that the costs of switching are vastly outweighed by the benefits. This implies that the market is locked in to an inferior standard.

This example has been hugely influential. Nearly every theoretical paper on standards wars mentions it at least in passing. Other examples exist, most notably the standards war between the Betamax and VHS VCR standards, in which the argument is that Betamax lost despite superior standard. But QWERTY remains the most common example.

\footnotetext{
${ }^{17}$ Katz and Shapiro also consider firms' compatibility and licensing decisions, but since these involve compatibility choice I do not discuss them here.

${ }^{18}$ Allowing consumers to consider the effect that their decisions have on the adoption decisions of others resolves the multiple equilibrium problem in their model.
} 
This is important because the validity of the QWERTY story has come under question. Liebowitz and Margolis (1990) present contrary evidence suggesting that the superiority of alternative keyboards has never been firmly established. They note that classic tests of the leading alternative (the "Dvorak") are in retrospect inconclusive and possibly tainted by the influence of Dvorak himself, who held a patent on his design. ${ }^{19}$ Nor is the critique restricted to the QWERTY example. Arguments have also been made that Betamax was in fact an inferior VCR standard and that this, rather than lock-in and inertia, explains the dominance of VHS. ${ }^{20}$

Unfortunately, the arguments above are based on somewhat anecdotal evidence. Given the paucity of hard evidence regarding the QWERTY case, it is unlikely that the debate can ever be resolved conclusively. However, the debate raises the larger point that there exists little hard empirical evidence of lock-in. Given the strong policy prescriptions implied by the debate on excess inertia and lock-in, the scant evidence on these questions suggests that conducting empirical tests of lock-in stands as one of the most important areas for future research in standards. This is not an easy undertaking. Lock-in and inertia are extremely difficult to identify. Because standards are not priced in the traditional sense, their impact on welfare is difficult to measure. Furthermore, comparing welfare under different standards requires careful counterfactual analysis because when trends toward standardization are strong, it is most common to only observe market performance under the winning standard. Later in this survey I discuss some encouraging recent empirical work on this front.

\subsection{Other rejoinders to the early literature}

Beyond the debate regarding QWERTY's validity as an empirical example, a larger intellectual debate has grown up in the wake of the early literature on standards

\subsubsection{Direct vs. indirect network effects as sources of inefficiency}

A first argument is that the specification of network effects in the literature has overstated the extent to which they generate inefficiency; this implies that excess inertia or momentum are less likely to exist. ${ }^{21}$ The argument hinges on the difference between indirect and direct network effects, and a claim that many standards are characterized by indirect network effects. This is important because in their simplest specification, indirect network effects are pecuniary or market-mediated. ${ }^{22}$ For example, a market-mediated network effect arises when two firms operate on the same standard and consequently produce products that have complementary demands. An example might be a computer operating system producer and a separate company writing software for that OS. In such a case, an inefficiency will arise because the firms will not consider the effect generated by their pricing on the profitability of the firm producing the complementary product.

\footnotetext{
${ }^{19}$ An even more compelling argument that the persistence of the QWERTY keyboard does not stem from network effects is raised by the fact that any individual user can now re-program a computer keyboard in any configuration and re-train privately. This suggests that the private costs of re-training at the individual level are greater than the private benefits.

${ }^{20}$ See Liebowitz and Margolis (1996) for more detail on the Beta/VHS case history.

${ }^{21}$ This discussion and that below on sponsorship draw from Katz and Shapiro (1994) and Liebowitz and Margolis (1994).

${ }^{22}$ Below I discuss richer models in which indirect network effects are not completely market-mediated because they affect product variety.
} 
An important dimension of this argument is that the degree to which indirect network effects generate inefficiency is a consequence of market structure. For example, there will be no inefficiency if markets for the two products are perfectly competitive. Inefficiencies will arise if the products exhibit economies of scale over the range of demand, but two-part pricing or volume discounts can mitigate them (with the associated distributional consequences). ${ }^{23}$ If firms can internalize indirect network effects through integration they can also mitigate inefficiencies. For example, banks have integrated into markets for both ATM cards and ATM machines, internalizing (at least partially) the indirect network effect between these two services. Even when firms do not integrate, they can solve the problem of indirect network effects by forming joint ventures or writing other contracts that align their incentives properly. ${ }^{24}$ As a point of contrast, where the network effect is direct, inefficiencies are more likely to arise regardless of market structure or the degree of integration.

\subsubsection{Sponsorship and commitments}

A second point related to the early literature is that the early models often consider the adoption of unsponsored standards. In some cases, sponsorship of a standard might solve some of the problems associated with inertia and lock-in. For example, the monopoly owner of a standard would have a greater incentive to subsidize consumers' adoption, because it would appropriate the rents from moving to the more efficient standard. For example, banks have formed shared ATM networks (such as Star, Plus and Cirrus) as joint ventures to internalize the network externality associated with allowing customers access to any banks' ATM machines, and create a sponsor for the standard. Another way of solving problems is through commitments to pricing and the development of reputations. ${ }^{25}$ This can have two effects. One is to reduce uncertainty. The other is to convince consumers that their adoption of a standard will not be exploited through hold-up or stranding.

\subsubsection{Key assumptions of the early models}

Another line of discussion regarding the early models is that they generate lock-in and excess inertia through overly restrictive assumptions. ${ }^{26}$ One example is that in Arthur's (1989) model, adopters' payoffs depend only on what previous adopters have done, and not on what future adopters will do. This means that adopters can forecast that their adoption decision will lead to lock-in on an ex post inefficient standard, but do not care. A second assumption is that in many early models, the timing of adoption is exogenous, and demand for new standards is inelastic. Allowing consumers to shift their adoption intertemporally, or decline adoption altogether, might improve market outcomes.

\subsubsection{Policy prescriptions and improving on market outcomes}

A final point following the early literature is that even in instances where the market would move too swiftly or slowly between standards, a policymaker will have difficulty improving upon the market. ${ }^{27}$ For instance, when there is uncertainty regarding the benefits

\footnotetext{
${ }^{23}$ Chou and Shy (1990) present a model in which economies of scale lead to inefficiency in markets with indirect network effects.

${ }^{24}$ There is a tension between the benefits accruing from integration and the antitrust issues involved with such cooperative behavior. The recent antitrust cases against Mastercard and VISA hinge on this issue.

${ }^{25}$ See Katz and Shapiro (1994) for a discussion of these issues.

${ }^{26}$ This discussion draws from Liebowitz and Margolis (1995).

${ }^{27}$ See Liebowitz and Margolis (1995).
} 
that would accrue from adoption, or which standard will achieve adoption first, a policymaker can improve on the market outcome only if it possesses superior information. Moreover, little is known about the positive aspects of standard-setting. For example, a policymaker may resolve uncertainty more quickly than would be the case in a standards war but also might be more likely to choose the "wrong" standard.

\subsection{Later work and its implications}

Since the earliest work on lock-in and inertia, a good deal of research has emerged that bears directly on one or more of the issues raised in the discussion above.

\subsubsection{Direct and indirect network effects}

As mentioned above, most models of standard adoption have focused on simple cases in which consumers face direct network externalities. Consequently, little has been known about whether the intuitions from models with network externalities can be applied to markets with indirect network effects. This issue has been taken up by Chou and Shy (1990) and Church, Gandal and Krause (2002), who argue that indirect network effects may cause true externalities in hardware/software markets where consumers purchase complementary components of a system and assemble them into system goods. ${ }^{28}$ Church, Gandal and Krause (2002) note that the externality will operate if the following assumptions hold: (1) software production exhibits increasing returns, (2) there is free entry in software, and (3) consumers have a preference for variety. This is an important point for two reasons. First, it seeks to provide a clear case in which indirect network effects might per se generate inefficiency. Second, establishing a rough theoretical (micro)equivalence between direct and indirect network effects implies that many of the lessons from the early standards literature, which were cast in terms of direct network effects, can be applied to markets with indirect network effects.

The particular issue of standards adoption in markets with indirect network effects has also received attention. Church and Gandal (1993) examine a model in of oligopolistic (i.e. sponsored) hardware and software competition, in which hardware and software are produced by different firms. In their model, hardware firms differ in their marginal cost and in the fixed cost associated with software development on their standard. This second cost is particularly important, as the indirect network externality operates through the number of software varieties available. The number of varieties depends on software's fixed costs, and the demand for software as determined through hardware pricing. In a line of questioning similar to that in Katz and Shapiro (1986), they ask whether the market will sometimes adopt an inferior standard. They find this to be the case; a standard with lower software fixed costs may be adopted by the market, although the other standard could yield higher social welfare if priced by a regulator.

Church and Gandal (1996) present an alternative model that also involves sponsorship, although it differs in that single integrated firms sell both hardware and software. They consider whether an incumbent (monopoly) supplier of hardware and software can deter

\footnotetext{
${ }^{28}$ The terms hardware and software refer to situations in which consumers purchase one (usually) durable component - hardware - and may match it with more than one complementary component - as is the case, for example, with literal hardware and software, but which is also true about operating systems and word processing programs. Church and Gandal (1993) consider a setting in which hardware and software are provided by separate firms, while Church and Gandal (1996) consider a setting in which hardware and software are provided by integrated firms.
} 
entry by a superior standard. The key parameter in their model is the "monopoly premium" - the difference between the monopoly and duopoly prices. When this premium is large, the market can settle on the wrong (incumbent) standard; this is qualitatively similar to excess inertia. Interestingly, this result does draw a distinction between indirect and direct network effects - for the latter, excess inertia seems less likely from a theoretical perspective. Church and Gandal explain this distinction by noting that it is the hardware producer's ability to commit to software production that gives it an advantage, by granting it a large installed base.

Clements (2002) provides another comparison between direct and indirect network effects, for the case in which there are two competitive hardware providers and a free-entry software market characterized by economies of scale. Clements concludes that direct and indirect network effects operate differently; direct network effects are more likely to yield insufficient incentives for the market to settle on a single standard, while indirect effects are more likely to provide excessive incentives. The second result stands in contrast to the conclusions in Church and Gandal (1996); this exists because of differences between the models, in their specification of hardware competition and the effects of software variety on consumer welfare. ${ }^{29}$

\subsubsection{Sponsorship, pricing and network ownership}

There has also been a recent wave of work focusing on sponsorship of standards. Clements (2003) examines whether sponsorship can solve excess inertia and momentum. His dynamic model considers a situation in which consumers in different "generations" consider the contemporaneous benefits accruing to others through their adoption and coordinate accordingly. Consumers do not, however, consider benefits accruing to past or future generations. This framework is therefore similar to that in Katz and Shapiro (1986). Clements notes that when consumers are homogeneous, sponsorship guarantees efficient adoption; there is no such guarantee in the unsponsored case. However, when Clements allows for consumer heterogeneity he finds that markets move too swiftly or too slowly between standards even if they are sponsored. This inefficiency persists because even a monopolist is unable to efficiently transfer surplus across different generations of consumers. Clements considers a number of extensions limiting sponsors' behavior, such as a constraint that prices must be nonnegative, or a limitation on the length of the sponsorship period after which the standard becomes open. He suggests that these extensions would bias the market toward excess inertia.

A related literature on platform competition has begun to delve even further into the complexities of sponsorship. This literature uses the term platform to refer to the medium through which buyers and sellers interact in a market with network externalities; the literature also refers to these as two-sided markets. ${ }^{30}$ For example, Rochet and Tirole (2001) mention that video game console makers must simultaneously attract consumers and software developers, each of whom values adoption more as the other side of the market grows. The other "sides" are the installed customer base from developers' perspective and software variety from the customers' perspective. One can easily view this

\footnotetext{
${ }^{29}$ Church and Gandal (1996) assume that consumers benefit directly from software entry, as they purchase more than one variety of software. Clements (2002) assumes that consumers purchase one variety of software. The strategic behaviour of hardware producers in Church and Gandal (1996) also affects the market outcome.

${ }^{30}$ Evans (2002) provides a survey of the economics of two-sided markets.
} 
setting as similar to standards competition, where platforms are analogous to sponsored standards.

The questions addressed in the platform competition literature are a bit different from the questions of interest in the literature on standards wars. For example, models of platform competition typically assume a particular market structure among competing standards rather than allowing competition between standards..$^{31}$ Nonetheless, the platform literature does offer insight into some unresolved issues in the standards literature. For example, the platform literature often models more sophisticated forms of pricing such as two-part tariffs, volume discounts and other forms of nonlinear pricing. Because much of the literature on standards models markets with high fixed costs and constant marginal cost, it seems reasonable to think that examining these issues would be insightful.

\subsubsection{Broader specifications of the standards war}

Another promising line of recent research considers richer specifications of consumer and firm behavior than those in the early literature. Choi (1994) models the option of waiting, where adopters can defer their adoption decision until learning more about the competing standards. The network externality in his model is what might be termed generational, in that it captures the failure of current adopters to consider the effects of their actions on past or future adopters. ${ }^{32}$ Choi does allow adopters to forecast how their and others' actions will affect future benefits to adopting one standard or another, and act accordingly. In this respect his model is richer than Arthur's. Interestingly, he finds that there are excessive incentives for early adoption.

Choi and Thum (1998) also examine waiting, focusing on the impact of sponsorship; they examine the adoption of standards, both when markets are competitive and when markets are monopolistic. ${ }^{33}$ Choi and Thum extend the Katz and Shapiro (1986) model by allowing consumers to wait for the new standard rather than commit to the old standard. The insight of this extension is that there is "insufficient waiting"; when an optimal strategy involves waiting for the superior new standard, consumers will adopt the current inferior standard because they do not consider the benefit they would generate for future adopters. This represents excess inertia of a sort, because the new standard does not achieve universal adoption when it should, and occurs when the new standard is competitively supplied. In contrast to the result in Katz and Shapiro (1986), Choi and Thum also find that a monopolistic owner of the new standard may worsen insufficient waiting; because the monopolist will set high prices for the new standard, waiting becomes less attractive to consumers. ${ }^{34}$

Shy (1996) presents a model that incorporates varying consumer preferences over the quality of standards and varying sizes of standards' installed bases. Shy also uses an overlapping generations framework to conduct the analysis, which is richer than the

\footnotetext{
${ }^{31}$ As an example, Rochet and Tirole (2002) first examine a benchmark market with one platform, then compare it to another market with competing platforms. This does not explicitly address the issue of whether the market chooses platforms efficiently.

${ }^{32}$ Current adopters generate useful information about the quality of each standard by adopting now, but do not value that information. Nor do they consider that adopting a standard different from that adopted by prior adopters "strands" those who have already adopted.

${ }^{33}$ Competitively and monopolistically supplied standards correspond to unsponsored and sponsored standards.

${ }^{34}$ Because the monopolist does not offer the new standard early in the game, it is unable to transfer surplus across time by pricing low initially to spur adoption.
} 
standard two- or three-period models used in much previous work. Shy's focus is on the speed of technological change rather than the existence of inertia or momentum, but his work does have promise in modeling a fuller model of consumers' and firms' intertemporal decision-making in standards wars.

A distinct but complementary line of work has begun to address the problem of choosing between multiple equilibria. The theoretical literature on "global games" examines the question of how equilibria are chosen in games with multiple equilibria. ${ }^{35}$ The applicability of this literature to standards problems is straightforward, and its contribution seems clear: it can improve our understanding regarding the degree to which we think coordination failure hinders adoption of superior standards.

Recent work by Ostrovsky and Schwarz (2002) applies insights from the literature on global games to a standards problem. ${ }^{36}$ There are two main results from their work, one that might be viewed as encouraging and one discouraging. The encouraging result is that in a game with multiple equilibria, noise in the adoption process may reduce the number of potential equilibria, thus simplifying the problem. ${ }^{37}$ The discouraging result is that while noise pins down the number of possible equilibria, a trivial amount of noise still causes excess inertia. Another contribution of Ostrovsky and Schwarz's work is in their attempt to identify the market parameters under which a superior standard is "viable" - i.e., that it will be adopted even in the face of uncertainty in the adoption process.

While this literature is still fairly incipient, it is encouraging that it seems to offer some ability to improve our understanding of circumstances in which markets can efficiently choose standards. Future work viewing standards problems as global games should prove fruitful.

\subsubsection{Modeling non-market processes of standards choice}

Another area that has made progress is the explicit modeling of either committee-based processes of standards choice, or the ability of a policymaker to improve on market-based outcomes. This is particularly important given that most standards wars are in fact resolved by consensus of some sort through an industry standards body.

One of the few studies of non-market processes of standard-setting is Farrell (1996). Farrell studies the performance of standard-setting bodies, focusing on the tradeoffs between the delays inherent in achieving consensus and the benefits of avoiding a costly standards war. His key notion is of "vested interests", which are asymmetries between the payoffs of the "winner" and "loser" after a standard has been adopted (the winner is that whose proposed standard is adopted). These vested interests cause delay and impede consensus. Farrell discusses how strategies to reduce vested interest can improve outcomes; he mentions a number of these, including forcing early standardization and requiring that owners license their standard as a condition of its ratification by a standards body. Farrell $(1989,1995)$ discusses a similar point in a less formal way, suggesting that

\footnotetext{
${ }^{35}$ See Morris and Shin (2002) for a survey of this literature.

${ }^{36}$ The Ostrovsky and Schwarz model is not a global game in the precise sense; however, it is similar in spirit.

${ }^{37}$ Ostrovsky and Schwarz define noise as uncertainty in compliance times. Compliance time is the lag between the decision to adopt and actual adoption (where it is only the latter that generates benefits for other adopters).
} 
weakening intellectual property protection can help markets settle on correct standards more quickly. ${ }^{38}$

Cabral and Kretschmer (2002) is one of the few studies to explicitly model policy design in standard-setting. Cabral and Kretschmer use the Arthur model as their baseline, with the major difference being that consumers have different preferences over the (two) competing standards. They model the policymaker as having (initially) imperfect information regarding which standard is preferred by more consumers. The policymaker gains information regarding which standard is preferred by observing consumers' sequential adoption decisions. It is therefore valuable for the policymaker to delay "lockin" to the standard in order to acquire better information. This incentive can in fact cause the policymaker to support the "lagging" standard, where the lagging standard is one with fewer adopters at any point in time.

Beyond this work, there has been little other formal examination of non-market processes in determining standards. ${ }^{39}$ This seems like a fruitful area for future research. It would be useful, for example, to see a model that captures the benefit that a standards body or public agency has on resolving potential adopters' uncertainty when they can delay committing to a standard. Anecdotally, this effect of uncertainty is viewed as a serious issue in standards wars. ${ }^{40}$ Another area that might inform policy is an examination of the institutional structure of standards bodies. ${ }^{41}$ Work on the "economic theory of regulation" has deepened our understanding of how competition between interest groups affects regulatory outcomes. ${ }^{42}$ Again, there is anecdotal evidence that standards bodies often serve as forums for this interest group competition. For example, if a standards body is not representative of all market participants affected by standard-setting, it may settle on a standard that is inefficient from society's point of view.

\subsubsection{Empirical studies of network effects and standards}

A particularly encouraging recent development has been the application to network industries of up-to-date empirical demand estimation techniques. This structural approach allows researchers to estimate consumer and social welfare under certain well-defined assumptions, and also lends itself to the counterfactual analysis required for examining standards wars. An example of this line of research is a recent paper by Ohashi (2003), which estimates the importance of network effects in the VHS/Beta standards battle. ${ }^{43}$

\footnotetext{
${ }^{38}$ The primary focus of his discussion - particularly in the 1989 piece - is on compatibility and whether markets achieve efficient levels of adoption rather than markets' choice between competing standards, but the intuition applies.

${ }^{39}$ Farrell and Saloner (1988) compare the performance of committees to that of markets, in an attempt to better understand the situations in which industry standards bodies can improve on market outcomes. They committee's purpose is to allow pre-adoption communication, while the market exhibits less communication and allows firms to unilaterally commit to a standard. The issue they examine is a bit different from that discussed here, in that both competing standards are equally attractive from society's point of view but failure to coordinate on a common standard is harmful. They find that committees delay coordination but can improve outcomes by helping choose the better standard more often.

${ }^{40}$ The competition between British Satellite Broadcasting and Sky TV in satellite television is a well-known example. BSB and Sky offered incompatible formats. The fact that consumers could not forecast the winning standard was cited as a reason for the slow penetration of satellite TV in the United Kingdom.

${ }^{41}$ Weiss (1993) makes a similar point.

${ }^{42}$ The economic theory of regulation derives from work by Becker (1983), Peltzman (1976) and Stigler (1971).

${ }^{43}$ This paper is part of a larger recent literature using structural techniques to estimate the importance of network effects. Rysman (2000) examines network effects in the Yellow Page industry, and Nair et al.
} 
Ohashi estimates the strength of the relationship between each standard's installed base and consumer demand for each standard, finding economically significant indirect network effects. Ohashi is able to use these estimates to calculate the size of the benefit from standardization, and also to examine what would have happened had SONY (the owner of the Beta standard) priced its VCRs differently. An interesting result of the analysis is that while it appears that consumers valued the VHS standard early in the battle, it would have been possible for Beta to capture the market if it had used its first-mover advantage to build an installed base through low pricing.

Another interesting recent empirical study is Shankar and Bayus (2003). Shankar and Bayus examine the home video game industry, in which Nintendo and Sega offer competing incompatible standards. They estimate the strength of network effects stemming from installed base, focusing on possible asymmetry in the strength of these effects across the two standards (holding installed base constant). Their results suggest that the Nintendo standard generates stronger network effects, implying that it might overtake a firm (Sega) with a larger installed base.

This wave of empirical work is particularly encouraging given that theoretical models of standards wars can display varying outcomes. It is common, for example for models to exhibit excess inertia over some range of parameter values and insufficient friction over another. This ambiguity highlights the value of empirical work.

\section{Discussion and conclusions}

A reading of the literature on standards wars reveals an active debate regarding the degree to which markets move too quickly or slowly between standards. Most of this debate has taken place in the theoretical literature. The early work on standards wars identifies clear circumstances in which markets exhibit inefficient choices of and/or movement between standards. Over time, a debate has grown up around some of the finer points of these models. For example, the distinction between direct and indirect network effects appears important. The last decade has seen a continuation of the earliest work on standards wars that in many cases has clarified these issues, but leaves some important questions unresolved.

At this point, one of the largest gaps in the theoretical literature is the relative lack of work modeling the performance of standards bodies relative to markets. Because so many standards are set in practice through these bodies, the welfare effects of a better understanding of how standards bodies perform could be enormous. A similar gap exists regarding public sector standard-setting. Most existing work on standards examines the extent to which market outcomes are efficient. Little work exists clarifying the circumstances under which a policymaker might improve on the market.

Beyond the theoretical issues, it seems clear that hard empirical analysis of standards wars and the performance of standards bodies can be fruitful. Most existing work in the area has been limited to straightforward tests for the existence of network effects. ${ }^{44}$ As

(2003) estimate the magnitude of indirect network effects between Personal Digital Assistants (PDAs) and PDA software.

${ }^{44}$ Funk and Methe (2001) is an exception. They explicitly compare the effects of market- and committeebased processes on adoption of new standards. Another recent paper that deals with standards wars is Dranove and Gandal (2001). Dranove and Gandal find that the "preannouncement" of the DIVX standard 
discussed above, there has been some encouraging recent empirical work; in particular, state-of-the-art empirical techniques now allow the welfare calculations that are at the heart of the debate on standards. This provides reason to be optimistic that our understanding of standards wars will improve.

\section{$5 \quad$ References}

Arthur, W. B. (1989) "Competing Technologies, Increasing Returns, and Lock-In by Historical Events,” Economic Journal, 99: 116-131.

Arthur, W.B. (1996) Increasing Returns and Path Dependence in the Economy, Ann Arbor, MI: University of Michigan Press.

Becker, G. S. (1983) "A Theory of Competition Among Pressure Groups for Political Influence," Quarterly Journal of Economics, 98: 371-400.

Besen, S. and J. Farrell (1994) "Choosing How to Compete: Strategies and Tactics in Standardization,” Journal of Economic Perspectives, 8: 117-131.

Besen, S. M. and L. L. Johnson (1986) "Compatibility Standards, Competition, and Innovation in the Broadcasting Industry," Rand Report: R-3453-NSF, November.

Cabral, L. M. B. and T. Kretschmer (2002) "Standard Battles and Public Policy," mimeo, London School of Economics.

Carlton, D. and M. Waldman (2002) "The Strategic Use of Tying to Preserve and Create Market Power in Evolving Industries," RAND Journal of Economics, 33: 194-220.

Choi, J. P. (1994) "Irreversible Choice of Uncertain Technologies with Network Externalities," RAND Journal of Economics, 25: 382-401.

Choi, J. P. and C. Stefanadis (2001) "Tying, Investment and the Dynamic Leverage Theory," RAND Journal of Economics, 32: 52-71.

Choi, J. P. and M. Thum (1998) "Market Structure and the Timing of Technology Adoption with Network Externalities," European Economic Review, 42: 225-244.

Chou, C. and O. Shy (1990) "Network Effects Without Network Externalities," International Journal of Industrial Organization, 8: 259-270.

Church, J. and N. Gandal (1993) "Complementary Network Externalities and Technology Adoption,” International Journal of Industrial Organization, 11: 239-260.

affected the adoption of DVD technology. Saloner and Shepard (1996) examine the adoption of a new standard (ATM machines), although they do not discuss the efficiency of adoption. Gandal, Greenstein and Salant (1999) show that the diffusion of a new standard (the DOS operating system) was affected by the availability of complementary software, but similarly do not attempt to ascertain whether the transition was efficient. 
Church, J. and N. Gandal (1996) "Strategic Entry Deterrence: Complementary Products as Installed Base," European Journal of Political Economy, 12: 331-54.

Church, J. and N. Gandal (2000) "System Competition, Vertical Merger and Foreclosure," Journal of Economics and Management Strategy, 9: 25-51.

Church, J., N. Gandal and D. Krause (2002) "Indirect Network Effects and Adoption Externalities," mimeo, University of Calgary.

Clements, M. T. (2002) "Direct and Indirect Network Effects: Are They Equivalent?" mimeo, University of British Columbia.

Clements, M. T. (2003) "Inefficient Adoption of Technological Standards: Inertia and Momentum Revisited," mimeo, University of British Columbia.

David, P. (1985) "CLIO and the Economics of QWERTY," American Economic Review, 75: 332-337.

David, P. A. and S. Greenstein (1990) "The Economics of Compatibility Standards: An Introduction to Recent Research," Econ. Innov. New Techn., 1: 3-41.

Dranove, D. and N. Gandal (2003) "The DVD vs. DIVX Standard War: Empirical Evidence of Preannouncement Effects," Journal of Economics and Management Strategy, 12: 363-386.

Evans, D. (2003) "The Antitrust Economics of Two-Sided Markets," Yale Journal on Regulation, 20.

Farrell, J. (1989) “Standardization and Intellectual Property," Jurimetrics Journal, 30: 3550.

Farrell, J. (1995) "Arguments for weaker intellectual property protection in network industries," StandardView, 3: 46-49.

Farrell, J. (1996) "Choosing the Rules for Formal Standardization," mimeo, University of California Berkeley.

Farrell, J. and P. Klemperer (2003) "Coordination and Lock-In: Competition with Switching Costs and Network Effects," in eds. R. Schmalensee and R. Willig, Handbook of Industrial Organization 3. Amsterdam: North Holland.

Farrell, J. and G. Saloner (1985) "Standardization, Compatibility and Innovation," RAND Journal of Economics, 16: 70-83.

Farrell, J. and G. Saloner (1986) "Installed Base and Compatibility: Innovation, Product Preannouncements, and Predation," American Economic Review, 76: 940-55.

Farrell, J. and G. Saloner (1988) "Coordination Through Committees and Markets, RAND Journal of Economics, 19: 235-252. 
Funk, J. L. and D. T. Methe (2001) "Market- and Committee-Based Mechanisms in the Creation and Diffusion of Global Industry Standards: The Case of Mobile Communication," Research Policy, 30: 589-610

Gabel, H. (1991) Competitive Strategies for Product Standards. New York: McGraw-Hill.

Gabel, H. L. (1987) Product Standardization and Competitive Strategy, Advanced Series in Management, vol. 11. Amsterdam; Oxford and Tokyo: North-Holland; Elsevier Science, New York.

Gale, D. (1995) “Dynamic Coordination Games,” Economic Theory, 5: 1-18.

Gandal, N. (2002) "Compatibility, standardization and Network Effects: Some Policy Implications," forthcoming, Oxford Review of Economic Policy.

Gandal, N., S. Greenstein and D. Salant (1999) "Adoptions and Orphans in the Early Microcomputer Market,” Journal of Industrial Economics, XLVII: 87-105.

Grindley, P. (1995) Standards Strategy and Policy. New York: Oxford University Press.

Kahin, B. and J. Abbate (1995) Standards Policy for Information Infrastructure. Cambridge: MIT Press.

Katz, M. L. and C. Shapiro (1986) "Technology Adoption in the Presence of Network Externalities," Journal of Political Economy, 94: 822-841.

Katz, M. L. and C. Shapiro (1992) "Product Introduction with Network Externalities," Journal of Industrial Economics, 40: 55-83.

Katz, M. L. and C. Shapiro (1994) "Systems Competition and Network Effects," The Journal of Economic Perspectives, 8: 93-115.

Liebowitz, S. J. and S. E. Margolis (1994) "Network externality: An uncommon tragedy," Journal of Economic Perspectives, 8: 113-150.

Liebowitz, S. J. and S. E. Margolis (1995) "Path Dependence, Lock-In, and History," Journal of Law, Economics and Organization, 11: 205-206.

Liebowitz, S. J. and S. E. Margolis (1996) "Should Technology Choice be a Concern of Antitrust Policy?" Harvard Journal of Law and Technology.

Liebowitz, S. J. and S. E. Margolis (1990) "The Fable of the Keys," Journal of Law and Economics, 33.

Morris, S. and H. S. Shin (2000) "Global Games: Theory and Applications," mimeo, Yale University.

Nair, H., P. Chintagunta and J. Dube (2003) "Empirical Analysis of Indirect Network Effects in the Market for Personal Digital Assistants," mimeo, University of Chicago. 
Ohashi, H. (2003) "The Role of Network Effects in the U.S. VCR Market, 1978-86," forthcoming, Journal of Economics and Management Strategy.

Ostrovsky, M. and M. Schwarz (2002) "The Adoption of Standards Under Uncertainty," mimeo, Harvard University.

Peltzman, S. (1976) "Toward a More General Theory of Regulation," Journal of Law and Economics, 19: 211-248.

Postrel, S. R. (1990) "Competing Networks and Proprietary Standards: The Case of Quadraphonic Sound," Journal of Industrial Economics, 39: 169-185.

Rochet, J. and J. Tirole (2003) "Platform Competition in Two-Sided Markets," Journal of the European Economics Association, 1: 990-1029.

Rysman, M. (2003) "Competition Between Networks: A Study of the Market for Yellow Pages," forthcoming, Review of Economic Studies.

Saloner, G. and A. Shepard (1996) "Adoption of Technologies with Network Externalities: an Empirical Examination of the Adoption of Automated Teller Machines," RAND Journal of Economics, 26: 479-501.

Shankar, V. and Barry L. Bayus (2003) "Network Effects and Competition: An Empirical Analysis of the Video Game Industry," Strategic Management Journal, 24: 375-394.

Shy, O. (1996) "Technology Revolutions in the Presence of Network Externalities," International Journal of Industrial Organization, 14: 785-800.

Stigler, G. (1971) "The Theory of Economic Regulation," Bell Journal of Economics and Management Science, 2: 3-21.

Weiss, M. B. H. (1993) "The Standards Development Process: A view from Political Theory," StandardView, 1: 35-41. 